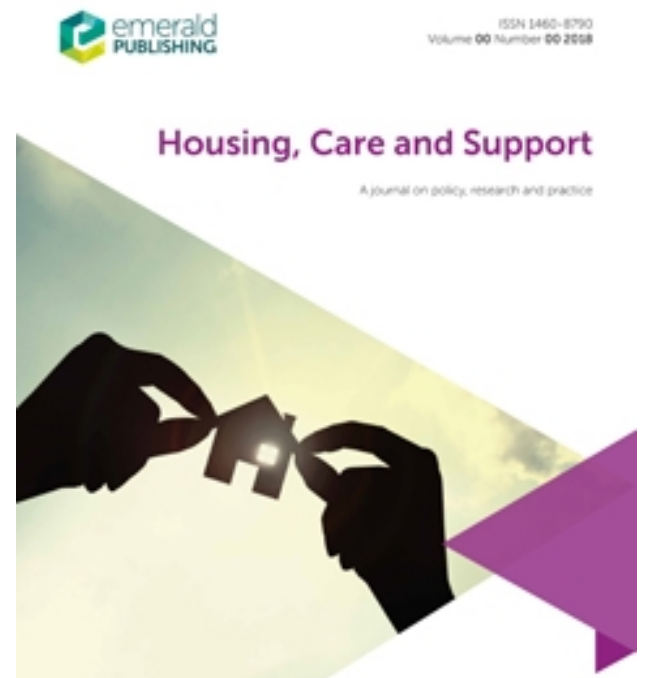

\title{
Social Impact Bonds in the UK homeless sector: Perspectives of front-line link workers
}

\begin{tabular}{|r|l|}
\hline Journal: & Housing, Care and Support \\
\hline Manuscript ID & HCS-08-2020-0011.R1 \\
\hline Manuscript Type: & Research Paper \\
\hline Keywords: & $\begin{array}{l}\text { Homeless, Homelessness, Services, Social Impact Bonds, Welfare, Link } \\
\text { workers }\end{array}$ \\
\hline \multicolumn{2}{|l}{} \\
\hline
\end{tabular}

\section{SCHOLARONE \\ Manuscripts}




\title{
Social Impact Bonds in the UK homeless sector: Perspectives of front-line link
}

\section{workers}

\begin{abstract}
Purpose - Social Impact Bonds (SIBs) have become a favoured way to fund public services, including housing, prison and homelessness projects, in an era of austerity. In a growing critical literature on SIBs, a largely absent voice is that of the link worker. The report focusses on the views of link workers in a SIB funded project which works with long term entrenched rough sleepers in the East of England.

Design/ Methodology/ Approach - Interviews with link workers were conducted with a thematic analysis echoing many of the views expressed in the critical literature about the problems, but also some of the advantages that SIBs offer to this type of project.
\end{abstract}

Findings - Three key themes were: discomfort with the funding mechanism; flexible and innovative interventions that SIBs make possible; and problems with the outcome measures that trigger payments. We conclude that if SIBs are to achieve their promise of providing funding which leads to effective solutions to deeply ingrained social problems, there needs to be more careful evaluation of their true benefits in comparison to publicly funded projects, adoption of more appropriate and project specific outcome measures; and a much clearer explanation and justification of the way in which SIB funding works.

Originality - Few studies have specifically explored the perceptions of link workers in the homelessness service. This study highlights the concerns but also benefits associated with the use of SIB as a funding mechanism within the homelessness sector. 
Key Words Homeless, Homelessness, Services, Social Impact Bonds, Social, Welfare, link workers.

Paper Type Research Paper

\section{Background}

Social Impact Bonds (SIBs) are a variant of 'payment by result' whereby a government contracts an organisation to design and deliver a welfare or social project and is subsequently paid based on achieving specific milestones or outcomes within the contract (Cabinet Office, 2012). In essence, SIBs aim to attract investors to bring increased spending on projects offering financial returns which are payable when social outcomes are achieved. As investors are only paid when agreed positive outcomes are achieved, the SIB funding is designed to transfer risk away from the public sector, providing greater freedom for organisations to be innovative, driving towards better performances through financial incentives (Brest et al., 2018). In theory, by increasing spending on preventative services, the interventions funded by SIBs can prevent greater spending on costly health and social care interventions further down the line, consequently providing a cost saving for the government. Across many countries, SIBs have become an increasingly common feature of social policy in the first part of this century. To date, the USA and the UK have been the most enthusiastic implementers, with 58 examples in the UK (Carter et al., 2018). Examples of social issues in the UK which have been tackled using SIBs include youth reoffending, prisoner recidivism and homelessness reduction (Nicholls and Tomkinson, 2013; Mason et al., 2017). Advocates of this mechanism point out that, given the total financial assets which exist in the hands of 
private investors, the potential amounts of capital available to invest in social problems are significantly greater with the use of SIBs than what can be brought to bear by governments, charities and not-for-profit organisations (Leventhal, 2013). The argument is made that if SIBs help to bring some of these assets to the funding of social projects which achieve positive outcomes, then this can only be a good thing which enhances what is already being done. This new approach brings extra resources and allows for innovation.

However, the SIB model of funding remains contested, and the rationale, and ideology behind this way of funding interventions has been the subject of much academic debate. Ethics, efficacy, and evidence base have all been heavily scrutinised and questioned (Fraser et al., 2020). Reviews suggest that, to date, there is little evidence that the model leads to any better or different outcomes than more traditionally funded programmes (Fraser et al.,2018a).

The UK was a pioneer in establishing the foundations of SIBs globally. In March 2010, HMP Peterborough Offending Service, in collaboration with the UK Ministry of Justice and local charitable trusts became the world's first pilot SIB (Disley et al., 2011). Delivered over a seven-year time period, the SIBs aim was to offer 3000 adult prisoners serving a short-term sentence of less than 12 months, intensive support both inside prison and after release helping them to resettle and reintegrate back into the community (Strickland, 2010). The specific innovation of the SIB, beyond usual offender support programmes was the intensity and breadth of support offered with police, probation, integrated offender management teams, the prison, the local authority, local statutory providers, training providers and the voluntary sector all 
offering support services, and the whole managed by one agency (Social Finance, 2017). Although the findings suggested positive changes through a reduction in recidivism and private investors were therefore repaid, the reductions were not sufficient to lead to savings on public spending by the Ministry of Justice (Ogman, 2016). Furthermore, whilst the project appeared to have worked well initially, it was much less effective in its latter stages due to a wider programme of policy changes e.g. Transforming Rehabilitation, which led to an unexpected early termination of the recidivism scheme (Disley et al., 2011; Ogman, 2016; Roy et al., 2017).

Homelessness remains a significant social problem, and there was a sustained increase in homelessness and a $141 \%$ rise in rough sleeping in the UK in the period from 2010 to 2019 (Wilson and Barton, 2020). London, with a rapidly growing population and particularly unaffordable housing, was the epicentre for homelessness, with $27 \%$ of all of the rough sleepers recorded in England (CHAIN, 2019).

As a response to the homelessness crisis in November 2012, the Thames Reach Housing Association and St Mungo's launched the world's first homeless SIB (Tan et al., 2015). The aim was to provide a personalised service pathway for a cohort of 415 entrenched rough sleepers and reduce the number of homeless individuals experiencing rough sleeping in London. There is no agreed definition of entrenched rough sleeper, but agencies accept that it refers to someone who has frequently slept outside over a period of months or years (Mackie et al, 2017). Raising over $£ 1$ million, this SIB provided a navigator approach, whereby key workers adopted a personalised and flexible approach, supporting the cohort to access a range of 
services; with targets to move individuals into sustained accommodation for at least 12 months. According to the Ministry for Housing, Communities and Local Government (MHCLG, 2019) there was a reduction in rough sleeping, with a move towards stable accommodation, sustained reconnection, reduction in accident and emergency admissions and progress towards employment, education or volunteering. The welcome reduction in homelessness and improvements to individuals may not only reflect the success of the SIB but also other changes which were introduced by The Homelessness Reduction Act 2017 and a manifesto pledge from the incoming government to eliminate rough sleeping by 2027 (Conservative Party, 2017). The timing of these early SIB projects (2010 for the offending project and 2012 for the homelessness one), coincide of course with an era of austerity and a clear government policy of significantly reducing public spending. The neo liberal response to the financial crisis of 2008 , to further shift responsibility for social problems away from government, and on to individuals played out in a range of initiatives. As Maier et al. (2018) have shown the New Public Management theory and similar ideas predicated on this shift from public to private have contributed to the cultural climate that led to the birth of SIBs.

The new homelessness legislation in 2017 was also accompanied by a number of start-ups of homeless SIBs across the UK. In that year a SIB was commissioned in Lincolnshire, known as ACTion Lincs Project, and delivered by $P 3$ a National charity and social enterprise who provided housing, financial and employment support. The Lincolnshire SIB, worth $£ 1.3$ million and funded by MHCLG, was one of eight successful SIB sites across the country. The P3-led project was the trailblazer project and is the result of a successful and innovative partnership with various 
providers including borough, district, city and county councils; a mental health foundation trust; an offender management service; and an addiction treatment provider. The project aims to be different in offering long-term intensive support, access to housing provided by local councils, whilst working more closely with a range of relevant public services.

The ACTion Lincs project is tasked with achieving a set of specific multifaceted outcomes for 120 entrenched homeless individuals aged 18+ years, with complex and co-occurring needs. The outcomes include facilitating and maintaining access to accommodation; extensive mental and physical health support; access to drug and alcohol treatment services; and help with access to training, education and employment. Available data suggests that the project has achieved positive outcomes (ACTion Lincs, 2020). Recruitment achieved was more than the target of 120. The 135 individuals who were supported had over 500 years of rough sleeping between them, and the majority were supported into secure tenancies. Fourteen moved away and 12 opted out; the remainder were all housed at September 2020. Fifty-eight had measurably improved health outcomes after being helped to engage with treatment for epilepsy, Hepatitis C, HIV or COPD. The team were clear that these outcomes would not have been achieved with a more standard homelessness project.

The mushrooming number and range of programmes which are funded by SIBs has been followed by a burgeoning critical literature which addresses a number of aspects of their nature and implementation. A recent review of this literature found 87 papers published between 2009 and 2015 (Fraser et al., 2018a) and noted a 
number of clear limitations and caveats evident from the available data. Reviewers noted that 'across all active SIBs, there has been very little rigorous counterfactual comparison of SIBs versus alternative methods of finance to deliver the same service ... and thus a lack of evidence of costs and benefits compared with the alternative approach to procurement' (Fraser et al, 2018a, p16; Fraser et al., 2018b).

In this growing SIB literature, it is evident there is little published work which offers any indication of the link worker's perspectives on the impact of this approach to funding, organising and evaluating homeless services. That gap provided the rationale for this study, which sought to privilege the perspectives of link workers.

The overall aim of the research project was to investigate front-line link workers views about the process and outcomes of the innovative Lincolnshire SIB, through a series of one-to-one interviews and a focus group. A recent publication described and assessed the general experiences and perceptions of staff in relation to this project, based on the same data (Rogers et al., 2020). This paper will focus specifically on their perceptions of the SIB funding mechanism.

\section{Methodology}

Focus groups provide one of the best methods for allowing individuals to share and compare their experiences with each other and to explore issues of shared 
importance (Bowling and Ebrahim, 2005). Additionally, focus groups allow for the explicit use of group interactions as research data, as well as individual participant responses to researcher prompts and questions (Morgan, 1998).

The focus group involved 10 participants, eight front-line link workers and two managers. There was an even split of five males and five females. The managers absented themselves for the latter part of the focus group discussion to enable for a freer expression of views by the link workers. The age of the participants ranged from 28 to 55 (mean=42). Working experience in the homelessness sector ranged from one to over 20 years.

Semi-structured interviews include a set of fixed questions, but few or no response codes, and are designed to ensure standardisation of questions for all participants, but also to allow the interviewer to probe and ask additional questions, and for the interviewee to raise additional issues (Bowling and Ebrahim, 2005). The interviews were conducted by one researcher (TG), audio-taped and transcribed verbatim. The interview guide and schedule used for this process was developed by the researchers following a comprehensive review of the literature, familiarity with the aims and context of the project, and findings from the focus group.

\section{Ethical Approval}

Permissions for the study were given by the University of Lincoln School of Psychology Research Ethics Committee (Code: PSY171821). All participants gave 
written permission for their data to be used, following provision of detailed participant information sheets.

\section{Data Analysis}

Thematic analysis was used to assess the total data set gathered from the focus group and individual interviews. This approach is suited to questions relating to people's experiences and to the ways in which people construct meaning from their experiences. Its purpose is to identify patterns of meaning across a data set (Braun and Clarke, 2006). To ensure the credibility and reliability of coding, transcriptions were independently reviewed and coded by both the first and third author and discrepancies were explored and resolved before key themes were agreed.

\section{Findings}

After independent scrutiny of the data by two researchers (TG and JR), and with the aid of NVivo software, three key themes emerged from the dataset: 1) Discomfort with the funding mechanism; 2) What SIBs make possible; 3) Problems with the outcome measures that trigger payments. The following section elaborates on these themes with selected statements from participants in the focus group (e.g. FGP1) or from interviews (e.g. IP2).

1. Discomfort with the funding mechanism

Discomfort with the nature of SIBs was expressed by a number of link workers across the one-to-one interviews forming a key element of discussion in the focus 
group session. 'I think ... the funding mechanism that's behind this project is .... I feel uncomfortable with it' (FGP3), and 'I don't support people making money ... off other people's misery' (FGP7) were two of many comments on the issue.

Several individuals elaborated on this in interviews.

"I am personally not keen on ... payment by results ... I think we can almost be blindsided by those targets and I think there is a worry there that people are going to start to work on ... what the companies ... needs are rather than those of the clients sat in front of you". (IP10)

"Part of the discomfort is a concern ... with the explicit focus on payment by results ... the funding mechanism....has an impact on the work, the relationship between the client and link worker from day one is almost transactional by nature ... we do brilliant work breaking down barriers by getting someone to be engaged and then once every three months we put a piece of paper in front of somebody and say you are worth $£ 1200$ to me today so can you sign that ... we have had examples .... where clients are saying 'well you only want to see me because I am worth money to you". (IP2)

These experiences appear to confirm the fears of a number of critics of approach to funding welfare services who contend that SIBs blur the boundaries between public, private and non-profit sectors (Miller et al., 2008) and translate social issues, such as homelessness, into business opportunities that will provide a financial return on investment (Cooper et al, 2016).

\section{What SIBs make possible}

A second, more positive theme, was about the funding mechanism. Despite discomfort and reservations, many link workers highlighted the achievements made 
possible for service users as a result of the way that the project had been structured.

They recognised that the ability to work intensively and to do what was necessary to achieve outcomes for service users, was afforded and enabled by the SIB.

\begin{abstract}
"The funding mechanism .... it is the first social impact bond that has looked at this particular problem ... this genuinely feels like a partnership collaboration across both housing and health, and whilst there are and have been frustrations still ... we have been able to unpick a lot of those because of ... those partnerships we have". (IP4)

"....one of the primary reasons why it has been successful is the ability to follow a person wherever they may be on their journey and not restricted by whether they be on the streets, in someone's home, in their own home, in prison, in hospital it has enabled them to uncover and unpick some of the complexities we didn't even know existed". (IP4)
\end{abstract}

Advocates of SIBs point to their utility as a novel approach to unlocking solutions to social problems (Wooldridge et al, 2019) and participants suggested that there was evidence of this in the project.

\begin{abstract}
"First and foremost, the opportunity that presents itself to even look at doing something because there is money available ... to do something very different. We had a group of people that were experiencing ... complex and multiple needs, not having access to development support services and actually we needed to do something different to ... meet their needs and this project ... enabled us to look at some of the problems across the system ... it gave us an opportunity to draw everybody together to ... try and put something in place to try and address this complex and wicked issue ... So that is a huge positive, without that we wouldn't have had this." (IP6)
\end{abstract}

The autonomy granted to workers can be seen as a function of the structure of the project but also seems to have been made more possible by the approach and attitude of the senior management towards the programme. 


\begin{abstract}
"Where I feel fortunate is right from Day one, I was given clear instructions from our senior management that we make sure that we do the right thing for that person and hopefully that should ensure we trigger the outcomes that enable us to get paid but if that doesn't then it is our job to feed that back to those that are commissioning us to deliver this project". (IP7)
\end{abstract}

The flexibility of SIB funding was considered by interviewees as innovative. In contrast to other funding sources where decisions about spending could be slower and more constrained, SIB resources were said to be made available quickly, in response to pressing service user needs. A certain amount of discomfort with the funding mechanism is balanced by a recognition of the advantages it may bring to the working practices of link workers, and in facilitating desired outcomes for service users. However, there is a further issue with SIBs, at least as they have been applied so far in the housing/homeless sector, which was articulated by a number of participants in this study below.

\title{
3. Problems with the outcome measures that trigger payments
}

The third and final theme relates to the suitability of outcome measures. Earlier, participant's views about the SIB funding mechanism were detailed. Discomfort was expressed at the way in which the payment by results mechanism within the SIB structure, led to a very explicit awareness on the part of service users and workers that funding for the continuation of the work carried out by project staff was contingent on the achievement of specified outcomes. Beyond the discomfort with the whole mechanism of payment by results was unhappiness with certain specific outcome measures which were seen as inappropriate, and/ or insensitive. 
Key outcomes measures which had been set and which triggered payments for this project, related to: achieving secure accommodation at key time points from 3 to 24 months; improvements in wellbeing, as measured by standardised assessment tools; entry into and sustained engagement with mental health and/or with alcohol misuse treatment; continuing with volunteering at 13 and 26 weeks; and continuing with part time or full time work at 13 and 26 weeks. These measures were selected and dictated by the MHCLG, and therefore local partners had no influence over these.

Participants commented on a number of these measures but in particular the scale selected to measure wellbeing as being inappropriate and possibly counterproductive.

"I haven't got any disagreements with [measures relating to securing accommodation] because it is good for us to keep track as well that is a nice little output, ... the only one I really have a proper grievance with is the Warrick-Edinburgh Wellbeing Assessment". (IP9)

Several other link workers also commented on this particular measure and some suggested alternatives that might be more useful to focus on.

"I don't think the Warrick-Edinburgh Scale it is a true reading of someone's feelings. I think there are better things to be paid for so results such as if they said they want to take their life in the last week that is a real result if they haven't". (IP6)

One participant was clear about the difficulties caused by the inclusion of this scale as an outcome measure:

"What we required from staff ... we know that things like the WarrickEdinburgh Scale Assessment is much of a nonsense. We are asking ... people things ...that are just weird. 'On a scale of 1-5 do you feel loved?' 'I have been sleeping on streets for 10 years mate, I still am 
what do you think'. We know the impact of that might have on the relationships that they are trying to build with people who historically have been through trauma who have struggled to build those relationships and it makes those relationships transactional". (IP10)

As noted above, key outcomes of the SIB included measures of wellbeing and engagement with mental health services. The absence of any measures relating to physical health seems to be a notable omission, as the extant literature is clear that the physical health of the homeless is significantly worse than average (Local Government Association, 2017; Weber et al., 2017; Cromarty et al., 2019). The health needs of the users of the service in this study were obvious to those working with them. Such issues formed a significant part of their work and they commented on the absence of any reference to this in the outcome measures.

"There is no recognition and you will obviously know this from the health audit that we have done, there is no recognition in terms of payment for physical health and there is a huge amount of work that goes on in terms of physical health". (IP4)

\section{Discussion}

Ambivalence towards, and a lack of a detailed understanding of, the SIB funding mechanism were evident among many of the link workers. There was also some scepticism and discomfort about SIBs as a method of funding. In a review of 
challenges experienced in relation to commissioning SIB's, Wooldridge et al (2019) note that a key issue for commissioners was suspicions and ideological concerns about SIB's on the part of stakeholders. They suggest most concerns are misplaced reflecting a lack of understanding of how SIBs work and the long-term benefits they provide. However, such scepticism about the process on the part of link workers echoes the majority view within the academic literature (Arena et al., 2016; Dowling, 2017; Maier and Meyer, 2017; Maier et al., 2018).

Despite the rapidly growing use of SIBs across a range of services which offer crucial interventions to some of the most vulnerable members of society, there remains a lack of evidence of their effectiveness and a range of concerns about their ethics and efficacy. A recent international review of the use of SIBs suggests that there is a paucity of concrete evidence about outcomes, where much of the reportage on SIBs is commentary and speculation (Fraser et al, 2018b). In terms of ethics, some academics have reported how SIBs within homelessness charities on occasion have ended up supporting some uncharitable behaviours (Cooper et al., 2016). The first SIB for homelessness in the UK, discussed earlier in this paper, involved, in some cases, investors receiving cash for the removal of foreign rough sleepers. In this case, the outcome measures were weighted towards removal of individuals from the streets rather than valued outcomes for the individuals themselves. 'Supporting clients into sustained reconnection to a country where they enjoy local connections' was a contracted outcome used to justify sharing confidential information with the Home Office and the use of charity staff to accompany individuals on deportation flights (Cooper et al., 2016, 71). This example 
illustrates in a very clear way the consequences which can follow from introducing such forms of conditionality into the funding of welfare programmes.

Several paradoxes have been identified in relation to SIBs. One is that many involved with them talk about both fidelity to evidence-based interventions and prescribed models but also a very flexible approach to meet the needs of service users. Of 51 SIB practitioner reports reviewed by Maier et al. (2018), 34 contained this paradox of 'evidence-based flexibility'. Perhaps this is not surprising. Lipsky (1980) first used the term 'street level bureaucracy' to highlight the way that front-line workers navigate the complexities and sometimes contradictory imperatives of policies and funders directives, and how in practice they have a degree of autonomy which they use to meet the needs of service users. This idea resonated and has been explored and confirmed in other studies. Hupe and Hill (2007) for example have explored the complexities of accountability that front-line workers have and suggest that "within the web of these multiple accountabilities which produce possibly contradictory action imperatives, street-level bureaucrats constantly weigh how to act" (290).

In deciding on actions, attempts to balance accountability to service users with that owed to employing agencies and funding agencies were certainly in evidence in our study of front-line workers.

Despite reservations expressed by participants in the present study, for most participants a pragmatic view prevailed, and link workers recognised that the SIB facilitated a service and a way of working which would not otherwise exist. There were reservations about the development of more transactional types of 
relationships; with further reservations about funding for the work being linked to an investment from which some persons or organisations might profit. Nevertheless, most interviewees were prepared to 'hold their nose', as it were, and accept the quid pro quo which enabled them to help service users achieve valued goals relating to accommodation, work, managing substance use and a range of other personal goals. The workers would aim to meet the outcome goals prescribed by the SIB but would use their street level knowledge to intervene in ways which would best meet outcomes that they and the service user deemed most relevant and valued.

In a separate paper the authors have shown how, despite performing a stressful and demanding role, link workers in this project report high levels of job satisfaction, and compared to sector averages, very few workers withdrew from the project (Rogers et al., 2020). Individuals largely attributed the satisfaction to the degree of autonomy and decision latitude which they were afforded in their role and to the ability to work long-term and intensively with a selected group of service users. It was the particular way the project was set up that enabled this, and the link workers recognised that it was, to a significant degree, the SIB that afforded and enabled this project to happen (Rogers et al., 2020). These findings support existing literature about staff wellbeing and retaining a skilled and flexible workforce (Cream et al., 2020, 43).

The other major theme which was developed by participants related to the inclusion of specific outcome measures, and the absence of others. The Warwick-Edinburgh Mental Wellbeing Scale (WEMWBS) was the target of particular criticism. The wellbeing scale is well validated across a range of general adult populations and cultures (Lloyd and Devine, 2012) and in specific groups such as adolescents and 
secondary mental health service users (Bass et al., 2016). However, it has not been validated for use with a homeless population and the evidence from this study suggest that at least some aspects are not appropriate and have questionable validity. Once funding is made dependent on outcomes, the relevance, reliability and validity of those outcomes becomes particularly important. The metrics used to measure outcomes in contemporary homelessness projects have been scrutinised in several studies and sometimes found to be lacking in relevance and validity (Johnson and Pleace, 2016).

In relation to physical health, current UK government policy emphasises the need for multi-disciplinary working and the need for all involved in health and social care to be alert to the physical needs of homeless populations. Recent guidance includes targets such as checking that homeless patients are registered with a GP and receive primary health care, vaccinations and screening programmes, and helping them to register when they are not. It also refers to providing holistic screening and health assessment, using tools such as the Queen's Nursing Institute (QNI) health assessment guidance (Public Health England, 2019). Such a policy was developed as a result of the increasing awareness of significant health inequalities between people affected by homelessness and other populations. Homeless populations have higher rates of acute and chronic health conditions (Local Government Association, 2017), and some $40 \%$ of the homeless are thought to have a long-term condition (Schanzer et al., 2007). Homeless individuals also have higher rates of emergency and acute hospital admissions, higher unmet health needs and elevated risks for a range of health conditions (Weber et al, 2017). All of this is reflected in the significantly lower life expectancy for a person affected by homelessness in England 
and Wales in 2018: 45 years for men and 43 for women, in comparison for an average of 76 years for men and 81 years in women in the wider population respectively (Local Government Association, 2017; ONS, 2019). Given this policy imperative, it is somewhat surprising that some targets relating to physical health were not included in the outcomes measures for this programme. As noted above the first SIB for the homeless sector aimed to develop outcomes relating to health and used A\&E admissions as a relevant proxy measure (Government Outcomes Lab, undated). It is unclear why any such measures were not included in the project that was the focus of this study

Beyond the specific issue of outcome measures relating to physical health, there are more general questions and problems relating to measurement and outcomes in projects of this nature. In a review of SIBs, McHugh et al, (2012) noted that social outcomes are notoriously difficult to measure, particularly those that relate to health and well-being as these types of outcome tend to be continuous rather than categorical. However, as the payment of financial returns is conditional on outcomes, in SIB funded projects, agreement and precision in relation to outcomes are required to avoid disputes.

This study has provided useful insights into the views of front-line link workers in a SIB funded project but is subject to several limitations. The first is that the data is limited to the views of one relatively small group of link workers in a single SIB funded project. As noted by Fraser et al., (2017) there is significant heterogeneity across SIB projects and the findings from this study cannot therefore be generalised to all SIB funded projects in this sector. The present study focussed on the attitudes 
and perceptions of staff, and a further limitation is that the views of service users themselves are not included. However, as noted at the outset, the existing literature on SIBs contains very little of the voice of staff working at the front-line of services, and this study makes an original contribution by offering a detailed understanding of the views of a staff group working in a flagship SIB project in the homeless sector. This perspective, from those who witness the realities of life for service users on a daily basis, is a vital one and adds nuance and detail to our understanding of the issues. These empirical perspectives can help to inform the rapidly evolving use of SIBs in work with people experiencing homelessness and in other public services.

\section{Conclusion}

The study demonstrated that in an innovative homelessness project, front-line link workers had mixed feelings towards the SIB that underpins it. The workers were suspicious of a model perceived as offering a financial gain to investors on the back of vulnerable members of society who are affected by homelessness. The workers were also concerned about inappropriate outcome measures; but fundamentally valued the work that this funding made possible. It is clear that the project achieved positive outcomes for most of the 135 individuals who were supported, with stable tenancies and improved health outcomes. The team were clear that these would not have been achieved with a more standard homelessness project. This contrasts with the review of published studies by Fraser et al (2017) found little evidence of any significantly different outcomes from SIB funded programmes compared to more traditional programmes. The same review suggests that studies of SIBs in the UK and elsewhere frequently point to the difficulties in reaching agreements as to what 
should be measured in the contracts. There does not yet seem to be the knowledge base or practice wisdom to develop appropriate agreements on the most appropriate outcome measures for SIB projects in particular areas of practice, especially in third section agencies such as homeless charities (Fraser et al., 2019; Fraser et al., 2020). As shown in this paper, front-line workers had clear and well-informed views about which of the mandated outcome measures were appropriate. The involvement of experienced staff in the co creation of outcomes measures may be a useful way forward for the development of future projects.

New evidence emerging in relation to outcomes from UK SIB funded projects is pointing to some reasons why commissioners may continue to pursue SIB models. In an evaluation of trailblazers SIBs in health and social care, the question of why commissioners might opt to pay the known higher transactions costs associated with SIBs was raised (Fraser et al.,2020). The answer given was that, "in the context of austerity, a SIB offers access to new financial streams and increased (non-financial) support for management and delivery of services up-front" (203).

However, if SIBs are to achieve their promise of providing funding which leads to effective solutions to deeply ingrained social problems, and to avoid them being resented by staff and service users who work within the services that are underpinned by SIB funding, several developments are required. There needs to be more evidence of their true benefits in comparison to publicly funded projects, adoption of more appropriate and project specific outcome measures; and a much clearer explanation and justification to all stakeholders of the way in which SIB funding works. 


\section{References}

ACTion Lincs (2020) Data on ACTion Lincs project [personal communication] e-mail to: T George, $12^{\text {th }}$ September 2020.

Arena, M., Bengo, I., Calderini, M., and Chiodo, V. (2016). "Social Impact Bonds: Blockbuster or Flash in a Pan?" International Journal of Public Administration 39: 927-39. doi:10.1080/01900692.2015.1057852.

Bass, M., Dawkin, M., Muncer, S., Vigurs, S., and Bostock, J. (2016) "Validation of Warwick-Edinburgh Mental Well-being Scale (WEMWBS) in a population of people using Secondary Care Mental Health Services." Journal of Mental Health 25(4): 323329. doi:10.3109/09638237.2015.1124401.

Bowling, A., and Ebrahim, S. (2005) Handbook of Health Research Methods: Investigation, Measurement and Analysis. London: McGraw-Hill (UK).

Braun, V., and Clarke, V. (2006) 'Using thematic analysis in psychology." Qualitative Research in Psychology. 3(2), 77-101. doi:10.1191/1478088706qp063oa.

Brest, P., Gibson, R.J., and Wolfson, M.A. (2018) "How investors can (and can't) create social value." Journal of Corporation Law 44:205.

Cabinet Office. (2012). Social impact bonds.

Carter, E., FitzGerald, C., Dixon, R., Economy, C., Hameed, T., and Airoldi, M. (2018) Building the tools for public services to secure better outcomes: Collaboration, Prevention, Innovation. Government Outcomes Lab, University of Oxford, Blavatnik School of Government.

CHAIN (2019) Combined Homelessness and Information Network London: CHAIN Annual Report Greater London 2018- 2019.

Conservative Party (2017) Forward, Together Our Plan for a Stronger Britain and a Prosperous Future. The Conservative and Unionist Party.

Cooper, C., Graham, C., and Himick, D. (2016) "Social Impact Bonds: The securitization of the homeless. "Accounting, Organizations and Society 55:63-82. https://doi.org/10.1016/j.aos.2016.10.003

Cream, J., Fenney, D., Williams, E., Baylis, A., Bahir, S., and Wyatt, H. (2020) Delivering health and care for people who sleep rough: Going above and beyond. The King's Fund. 
Cromarty, H., Johnston, N., Kennedy, S., Powell, T., and Barton C. (2019) Rough sleepers: access to services and support (England). Briefing Paper Number 07698. London: House of Commons.

Dowling, A. (2017) "In the wake of austerity: social impact bonds and the financialisation of the welfare state in Britain." New Political Economy, 22:3, 294-310. doi:/10.1080/13563467.2017.1232709.

Disley, E., Rubin, J., Scraggs, E., Burrowes, N., and Culley, D. (2011) Lessons learned from the planning and early implementation of the Social Impact Bond at HMP Peterborough. London: Ministry of Justice.

Fraser, A., Tan, S., Lagarde, M., and Mays, N. (2018a) "Narrative of promise, narrative of caution: A review of the literature on Social Impact Bonds." Social Policy and Administration. 52(1), 4-28.doi:10.1111/spol.12260.

Fraser, A., Tan, S., Kruithof, K., Sim, M., Disley, E., Giacomantonio, C., Lagarde, M., and Mays, N. (2018b) Evaluation of the Social Impact Bond Trailblazers in Health and Social Care Final Report. Technical Report. Policy Innovation Research Unit. Fraser, A., Tan, S., and Mays, N. (2019) "To SIB or not to SIB? A comparative analysis of the commissioning process of two proposed health-focused Social Impact Bond financed interventions in England“. Journal of Economic Policy Reform: 1-16. doi:10.1080/17487870.2019.1572508

Fraser, A., Tan, S., Boaz, A., and Mays, N. (2020) "Backing what works? Social Impact Bonds and evidence-informed policy and practice." Journal of Public Money and Management 40(3): 195-204.doi:10.1080/09540962.2020.1714303.

Government Outcomes Lab (undated) London Homelessness Social Impact Bond (Thames Reach)

Hupe, P. and Hill, M. (2007) Street-level bureaucracy and public accountability. Public Administration, 85: 279-299 https://doi.org/10.1111/j.1467-9299.2007.00650.x Johnson, G., and Pleace, N. (2016) How do we measure success in homelessness services? Critically assessing the rise of the Homelessness Outcomes Start.

European Journal of Homelessness, 10(1): 31-51.

Leventhal, R. (2013) "Effecting progress: Using social impact bonds to finance social services." NYU Journal of Law and Business 9(2),:511-534.

Lloyd, K., and Devine, P. (2012) "Psychometric properties of the Warwick-Edinburgh Mental Well-being Scale (WEMWBS) in Northern Ireland." Journal of Mental Health, 21(3), 257-263. doi:10.3109/09638237.2012.670883 
Local Government Association (2017) The impact of homelessness on health. A guide for Local Authorities.

Mackie, P., Johnsen, S., and Wood, J. (2017) Ending Rough Sleeping: What Works. London: CRISIS.

Maier, F., and Meyer, M. (2017) "Social Impact Bonds and the Perils of Aligned Interests." Administrative Sciences, 7 (3): 1-10.

Maier, F., Barbetta, G.P. and Godina, F. (2018) "Paradoxes of Social Impact Bonds." Social Policy and Administration. 52(7): 1332-1353. doi:10.1111/spol.12343

Mason, P., Lloyd, R., and Nash, F (2017) Qualitative Evaluation of the London Homelessness Social Impact Bond (SIB). Final Report. Department for Communities and Local Government.

McHugh, N., Sinclair, S., Roy, M.J., Huckfield, L., and Donaldson, C. (2012) "Social Impact Bonds: A Wold in Sheep's Clothing?" Journal of Poverty and Social Justice, 21(3):247-257. https://doi.org/10.1332/204674313X13812372137921

Miller, P., Kurunmaki, L., and O'Leary, T. (2008) “Accounting, hybrids and the management of risk. " Accounting, Organisations and Society, 33(7): 942-967. https://doi.org/10.1016/j.aos.2007.02.005

MHCLG (2019) Rough sleeping in England: Autumn 2018.

Morgan, D.L. (1998) The Focus Group Guidebook. London: Sage.

Nicholls, A., and Tomkinson, E. (2013) The Peterborough Pilot: Social Impact Bond. University of Oxford.

ONS (2019) Deaths of homeless people in England and Wales: 2018. Office for National Statistics

Ogman, R. (2016) "Social Impact Bonds: A "Social Neoliberal" Response to the Crisis?" In: Barbara Schönig \& Sebastian Schipper (eds.): Urban Austerity: Impacts of the Global Financial Crisis on Cities in Europe. Berlin: Theater der Zeit: 58-69.

Roy, M.J., McHugh, N., and Sinclair, S. (2017) "Social Impact Bonds - Evidence Based Policy or Ideology?" In Greve, B. (Ed,), Handbook of Social Policy Evaluation. Edward Elgar Publications, Northampton, MA.

Public Health England (2019) Homelessness: Applying All Our Health.

Rogers, J., George, T., and Roberts, A. (2020) "Working with individuals who have experienced homelessness: Stresses and Successes" Housing Care and Support, 23 (2). https://doi.org/10.1108/HCS-10-2019-0020 
Schanzer, B., Dominguez, B., Shrout, P.E., and Caton, C.L.M. (2007) "Homelessness, Health Status, and Health Care use." American Journal of Public Health. 97(3): 464-469. doi: 10.2105/AJPH.2005.076190

Social Finance (2017) World's first Social Impact Bond to reduce reoffending in Peterborough.

Strickland, P. (2010) Social Impact Bonds - the Pilot at Peterborough prison. Parliament UK.

Tan, S., Fraser, A., Giacomantonio, C., Kruithof, K., Sim, M., Lagarde, M., Disley, E., Rubin, J., and Mays, N. (2015) An Evaluation of Social Impact Bonds in Health and Social Care: Interim Report. Policy Innovation Research Unit (PIRU).

Weber, J., Lee, R.C., and Martsolf, D. (2017) "Understanding the health of veterans who are homeless: a review of the literature“. Public Health Nursing. 34(5): 505-511. doi:10.1111/phn.12338

Wilson, W., and Barton, C. (2020) Tackling the under-supply of housing in England. Briefing Paper Number 07671. London: House of Commons.

Wooldridge, R., Stanworth, N., and Ronicle, J. (2019) A study into the Challenges and Benefits of the Social Impact Bond Commissioning Process in the UK - Final Report. Birmingham: Ecorys. 